\section{THE EFFECT OF NAUHEIM BATHS UPON CARDIAC CONDUCTIVITY AND CONTRACTILITY.}

\section{BY LESLIE THORNE THORNE, M.D., \\ B.S. DURH., \&C.,}

LATE MEDICAL HXIMINER. LONDUN COUNTY COUNCIR TECHNICAL EDUCATLON BOARD.

IT will be impossible for many years to come for English patients suffering from the various forms of cardiac and circulatory diseases which are benefited by the Nauheim treatment to go to Germany for a course of baths, and those who have visited that spa on one or more occasions and have derived great benefit thereby will, no doubt, consult their medical advisers as to the possibility of obtaining the treatment in this country. Under these circumstances it seems an opportune moment to draw attention to some of the results obtained baths upon defective cardiac conductivity. Research in this direction was impossible before the invention of the polygraph, and it is to Sir James Mackenzie, the inventor of this ingenious and valuable instru ment, that we are indebted for a means of obtain. ing diagrammatic and accurate records of the varying conditions of cardiac conductivity, and of being able to observe the effects that are produced upon them by the administration of drugs and other forms of treatment.

The following cases with their respective polygraphic tracings are taken from a large number I have treated with the Nauheim methods in London, in all of which I have found defective conductivity to be distinctly benefited in conjunction with the general improvement in health which resulted from the treatment.

CASE 1. - The patient, a female aged 59 , had had an attack of influenza a year before I saw her, since which time she har suffered from pains over the region of the heart on the slightest exertion, dyspnoea, which was worse at night and caused her to spend sleepless nights sitting up in bed,

FrG. 1.

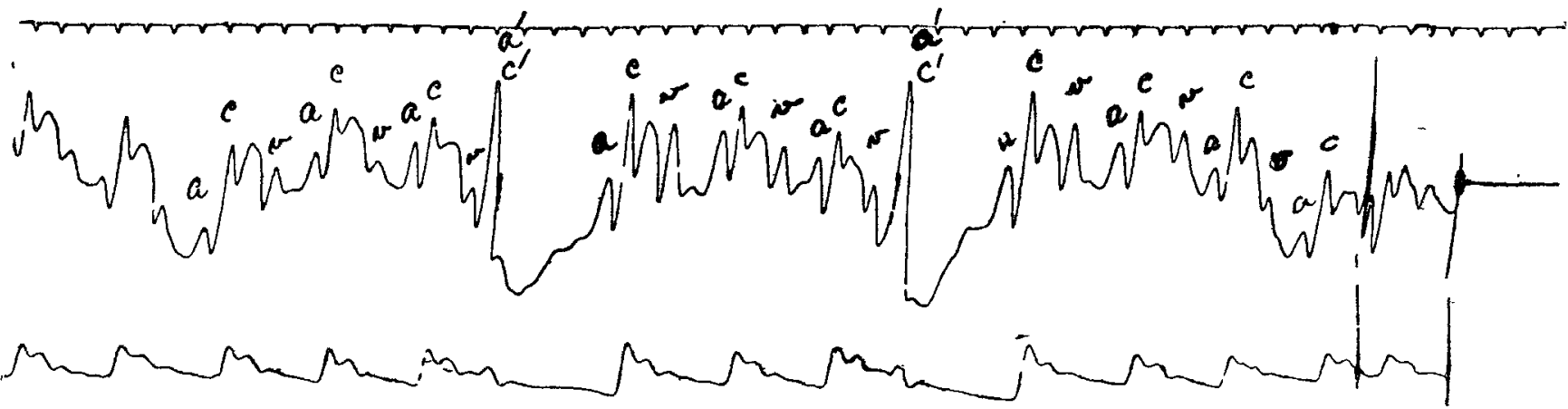

Polygraphic tracing of Case 1 before course, showing frequent premature auricular contractions.

from the application of the Nauheim methods in England, and to emphasise the fact that the treatment can be given in London or elsewhere quite as satisfactorily as in Germany.

The administration of the proper form of Naubeim bath in a suitable case produces a slowing and strengthening of the heart's action, a stimulation of the cardiac conductivity, and a definite lowering of blood pressure. Exactly similar results are obtained by the administration of a similar bath prepared artificially.

Careful investigations carried out with the aid of auscultation, percussion, and the sphygmomanometer have proved that in patients suffering from severe palpitation, and much distress from cardiac irregularity. She was unable to do anything, and had for months led an invalid life. When I first saw her her lips were cyanosed and she suffered from marked dyspnœa even whilst sitting in a chair. Her pulse was 84 per minute, and exhibited constant intermittences, which proved to be due to premature auricular contractions; it was small in volume. the tension was greatly increased, being $125-235 \mathrm{~mm}$. $\mathrm{Hg}$, and the vessels were tortuous and thickened. There was marked pulsation in the neck; the impulse at the apex was very forcible and diffuse, and the apex beat was $1 \frac{1}{3}$ inches to the left of the left nipple. The area of cardiac dullness measured $7 \frac{1}{2}$ inches across at the nipple level, extending from 2 inches to the right of the middle line to 1 inch to the left of the left nipple. The heart sounds were accentuated and a loud systolic murmur was heard over the aortic area.

Fig. 2.

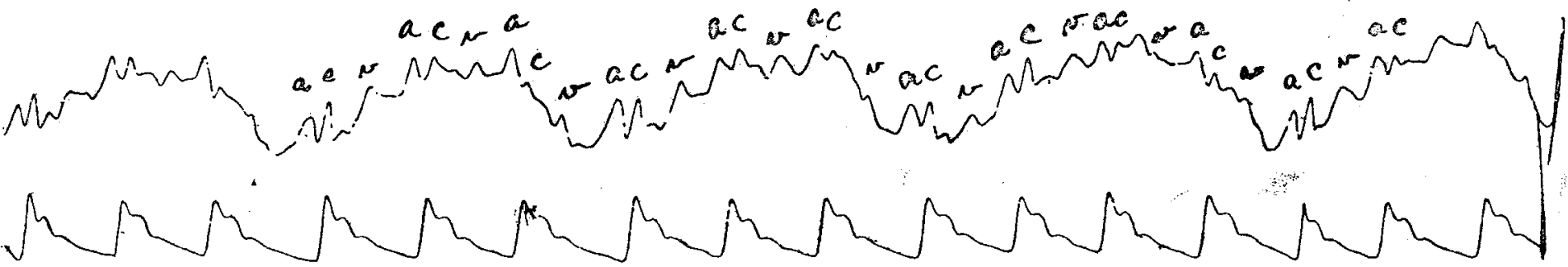

Polygraphic tracing of Case 1 after first bath, showing regular pulse of improved volume.

dilated enfeebled hearts, the result of myocardial or endocardial disease, the effects produced by a properly administered course of Nauheim baths are a toning up of the cardiac muscle, a greatly strengthened contractility, and a markedly reduced arterial tension in cases where hypertension is present, but has not advanced to that stage in which the vessels have so degenerated as to become practically rigid.

For some time past I have been carrying out investigations with regard to the effect of these
The legs and ankles were somewhat œdematous. The urine was of specific gravity 1015, but contained no albumin, sugar, or casts.' As the patient had had treatment by rest and drugs for many months and was not improving in health, I advised her to take a course of Nauheim baths and took her into a nursing home for this purpose, as she was too ill to have it in her own home. Fig. 1 is a polygraphic tracing taken before the first bath; it shows two examples of the frequent premature auricular contractions. The pulse-rate is 84 per minute and the volume of the pulse rather small. Fig. 2 is a polygraphic tracing taken ten minutes after the first bath; it shows a regular pulse of 
FIG. 3.

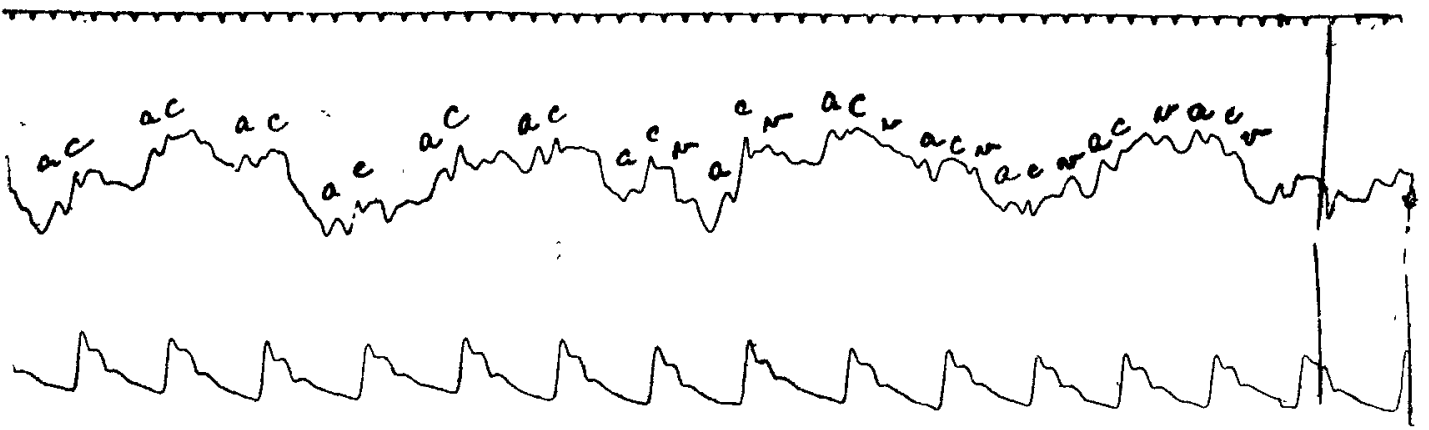

Polygraphic tracing of Case 1 after course, showing regular $x$ ulse of good rolume; rate $\in 8$. volume, and 70 per minute in the recumbent position. This patient had a course of 25 baths extending over a period of five weeks. At the conclusion of the treatment her weight was 15 st. $12 \mathrm{lb}$., having dropped 1 st. $2 \mathrm{lb}$. in the five weeks. Sle was of a good colour, the dyspncea was decidedly less marked, and she could take fairly lengthy walks of one or two miles extent. There was no oedema of the legs, and the bronchial catarrh was mucb improved volume and slower rate, 58 per minute. The less troublesome. The pulse was 90 in the erect and 68 in improved conductivity is demonstrated by the absence of premature auricular contractions.

After a course of 25 baths extending over five weeks the patient was in a much better state of health. She had no dyspnoea and could sleep well at night without any pain or palpitation; there was no cedema of the legs or ankles, and the blood pressure had fallen to $120-200 \mathrm{~mm}$. Hg, a.drop of $35 \mathrm{~mm} . \mathrm{Hg}$ in the maximum pressure. The area of cardiac dullness measured 5 inches across at the nipple level and extended from $1 \frac{1}{4}$ inches on the right of the middle line to $\frac{1}{2}$ inch inside the left nipple; the apex beat was in the nipple line; the cardiac impulse was much less forcible and diffuse. Fig. 3 is a polygraphic tracing taken at the end of the course and shows a regular pulse of fair volume and 68 per minute. Nine months after the treatment this the recumbent position. The area of cardiac dullness was markedly less, extending from 3 inches inside the left nipple line to the mid-sternal line. The position of the breast, which was large, had somewhat altered by the loss of weight, so that the nipple was not exactly in the same position, and the area of cardiac dullness had not decreased quite so much on the left as would appear from the measurements. The area of cardiac dullness was, however, about normal. The cardiac sounds were much stronger and could be well heard both at the apex and over the base of the heart; no murmur was audible at any time during treatment. The blood pressure was $80-130 \mathrm{~mm} . \mathrm{Hg}$, having fallen $20 \mathrm{~mm}$. since the commencement of the treatment. Fig. 5, a polygraphic tracing taken at the end of the course, shows in the venous curve an $a \cdot c$ interval slightly below the normal, and in the

FIG. 4.

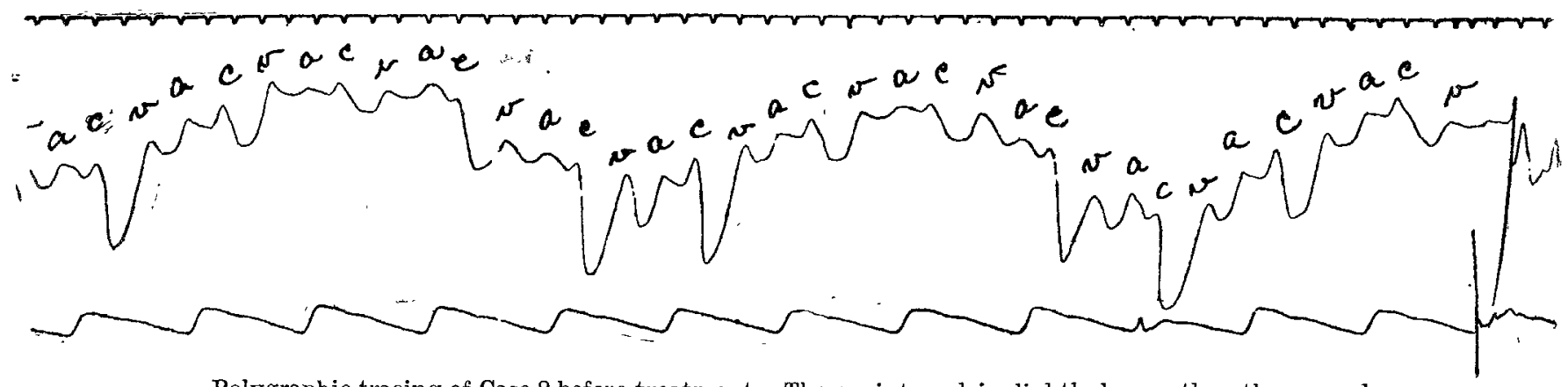

Polygraphic tracing of Case 2 before treatment. The $a-c$ interval is slightly longer than the normal. Pulse 70 per minute in recumbent position.

patient was still enjoying good health and her pulse was quite regular.

CASE 2.-The patient, a female, 58 years of age, consulted me on account of great stoutness, dyspnœa, bronchial catarrh, palpitation, and increasing odema of the legs. She was somewhat cyanosed, markedly obese, weighing 17 st., and being $5 \mathrm{ft} .10 \mathrm{in}$. in height; her dyspncea, even on the slightest exertion, was marked, and she could not walk except at a slow pace and for a short distance. The legs were decidedly cedematous up to the knees, pitting fairly deeply on pressure. Her pulse in the upright position was 96 per minute regular in time and volume, and of small volume; her blood pressure was $75-150 \mathrm{~mm}$. Hg. Her area of cardiac dullness was much enlarged, extending from 2 inches outside the left nipple line to 3 inches to the right of the mid - sternal line ; the cardiac sounds were heard very faintly at the apex, but were not audible over the base of the heart. There was no albumin or sugar in the urine. The polygraphic tracing: Fig. 4, showed in the venous curve an $a \cdot c$ interval slightly longer than the normal, and in the radial curve a regular pulse of very small radial curve a pulse of much improved volume and slower rate. The symmetry of the tracing is spoilt by the pens. meeting at times, but the central portion is clear.

The above two cases show the typical improve. ment obtained in cardiac conductivity and contractility by a course of Nauheim baths administered in London. Clinically they differ widely from each other and are thus illustrative of the fact that in the majority of cases suitability for the Nauheim treatment is rather a question of severity of the disease than of kind, though there are exceptions to this rule. The case of a dilated enfeebled heart in a patient with high blood pressure is a priori the one that gives the best results, and the fact that FIG. 5.

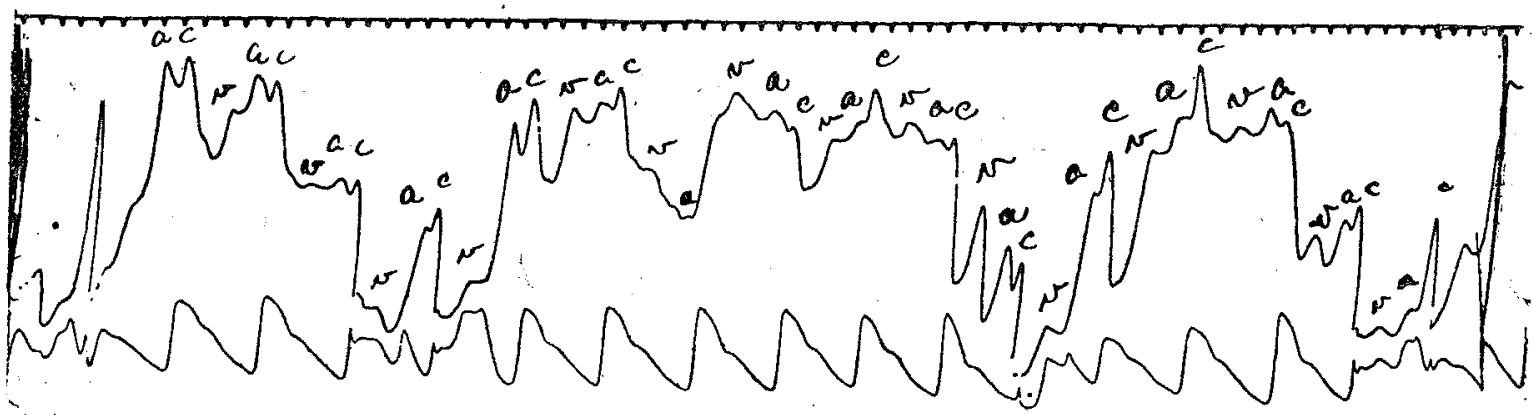

Polygraphic tracing of Case 2 after treatment. Pulse 68 per minute. The $a-c$ interval is slightly less than normal. 
valvular disease is also present is no bar to the treatment, though the valvular defect itself cannot be cured.

In Case 1 the effect of the baths upon the defective cardiac conductivity was very marked because the defect was very material. In Case 2, though the decrease in the $a \cdot c$ interval produced by the baths was only small, it must be remembered that that interval is normally only $1 / 5$ th of a second in duration, and that an increase of $1 / 15$ th to $1 / 20 t h$ of a second indicates a marked slowing of the conductivity.

In a large number of cases of cardiac and circulatory impairment the only indication of a defective conductivity is a slight lengthening of the $a \cdot c$ interval. When sufficient time has passed to allow observers to follow up such cases over long periods, I believe it will be found that this slight impairment is the first indication of a condition which, if untreated, leads ultimately to serious defects in the nervo-muscular mechanism of cardiac conductivity. At present this theory cannot be proved, but we are able to demonstrate the great improvement in the condition of the patient after the conductivity and contractility of the heart have been brought into a more normal condition by suitable treatment.

Harley-street, W.

\section{ANESTHESIA (GENERAL AND SPINAL) FOR SUPRAPUBIC PROSTATECTOMY.}

BY J. D. MORTIMER, M.B. LoND., F.R.C.S. ENG., ANASTHETIST, ST. PETER'S HOSPITAL FOR STONE AND OTHER URINARY DISEASES, HENRIETTA STREET, LONDON, W.C.

IT was long ago observed that under general anæsthesia, even when deep, reflex disturbances commonly accompanied certain proceedings such as dilatation of the sphincter ani.

In recent times it has been made more and more evident, both by clinical observations and by investigations in the laboratory, that anæsthetics given by inhalation do not annul nervous impressions due to injury, surgical or otherwise, although they more or less diminish or modify them; and that the consequent reactions vary considerably, both in degree and kind, according to the tissue or organ concerned.

Some years ago ${ }^{*}$ I drew attention to certain difficulties and dangers arising during prostatectomy under general anæsthesia (which was at that time alone employed). On distension of the bladder the straining which would occur were the patient not fully anæsthetised is sometimes represented by shallow, hesitating breathing, with prolonged expiration and secondary disturbance of the heart's action. Enucleation in a fairly vigorous patient acts as a powerful respiratory and circulatory stimulant, but in a feeble patient and in others when enucleation is prolonged, depression is the result. The proceeding is accompanied by an immediate and considerable rise in arterial blood pressure, ${ }^{3}$ and the ultimate general effects no doubt depend largely upon whether the heart is able to answer to the call. There may be contraction of the muscles of the lower jaw, tongue, and larynx, which will give trouble to the anæsthetist; and a special trouble to the surgeon may arise, rigidity of

1 Macewen : British Medical Association Meeting, 1904.

2 West London Medico-Chirurgical Journal, January, 1907.

3 Tyrrell Gray and Parsons, Arris and Gale Lecture, 1912. the recti abdominis and levatores ani, making his work difficult or for a time impossible.

It must not be supposed that these difficulties and dangers invariably occur. In nearly 300 opera tions done at St. Peter's Hospital for which I gave a general anæsthetic alone they were noted as having happened (usually only to a slight degree) in less than 12 per cent. Still, we must always be prepared for them; and it need hardly be remarked that when they do occur, the age, organic disorders, and general state of the patient usually add considerably to the gravity of the situation. To lessen these troubles I have found it answers much better in case of vigorous patients (after starting with chloroform) to give C.E. mixture just before and during enucleation, and in case of weakly ones to give the latter from the beginning, and to a few, ether by the open method during enucleation, to counteract the arterial constriction already mentioned, and provide a deeper anæsthesia (and therefore more complete relaxation) with less danger. Their absence can, however, according to our present knowledge, only be ensured by spinal analgesia; and this should always be used when for any reason general anæsthesia to the full extent is contra-indicated-for instance, when there is definite heart or lung or kidney disorder, obesity, alcoholism; and when there is probability that enucleation will be more than commonly difficult.

Mr. H. M. Page has pointed out that spinal analgesia not only prevents reflex disturbances which are inconvenient and may culminate in the condition commonly known as "shock," but is also less likely (than full general anæsthesia) to be followed by suppression of urine. As a rule, and especially when the patient is weakly or nervous, it is advisable to combine it with light general anæsthesia to avoid mental distress or "psychic shock" of which the effect in disturbing internal secretions and blood pressure has also in late years been demonstrated. Narcotics are not always admissible or effectual, and distress, if not present at the beginning, may be brought about later. In old men senile changes in the vertebral column and spinal membranes sometimes make penetration of the sac difficult and painful. The enucleation of a tough prostate is tedious, and although pain may not be felt there is sometimes discomfort and anxiety caused by the pressure on the lower part of the abdomen, and by a sensation of internal dragging. If a complication such as unusual bleeding occurs the consciousness of the patient is, to say the least, undesirable. Usually no anæsthetic is required after injection has been made, the patient remaining asleep.

In the last few years I have given at St. Peter's Hospital spinal analgesia alone in 26 cases and in combination with light general anæsthesia in 57 cases, using 2 c.c. or less of novocain and mannitol 5 per cent. solution. In 6 cases some temporary pallor and nausea came on about 20 minutes after injection; this has been noted by others, and is possibly due to novocain reaching the medulla by absorption, or to circulatory stasis in the lower limbs and abdomen. The Saccharin Corporation were good enough to have some experiments made for me (confirming my own) which show that a heavy solution of novocain and mannitol does not diffuse in a saline solution of low specific gravity. ${ }^{5}$

4 The Lancet, May 16th, 1915, p 1015.

The report is too long to include here, but I shall be pleas ad to send it to anyone in terested. 